\title{
The Application of Diabatic Heating in Q-Vectors for the Study of a North American Cyclone Event
}

\author{
Katie L. Crandall, ${ }^{1,2}$ Patrick S. Market, ${ }^{1}$ Anthony R. Lupo, ${ }^{1}$ Laurel P. McCoy, ${ }^{1,3}$ \\ Rachel J. Tillott, ${ }^{1}$ and Justin J. Abraham ${ }^{1,4}$ \\ ${ }^{1}$ Department of Soil, Environmental, and Atmospheric Science, University of Missouri, 302 E ABNR Building, \\ Columbia, MO 65211, USA \\ ${ }^{2}$ National Oceanic and Atmospheric Administration, National Weather Service, Operations Proving Ground, 7220 NW 101st Terrace, \\ Kansas City, MO 64153, USA \\ ${ }^{3}$ National Weather Service Portland Weather Forecast Office, 5241 NE 122nd Avenue, Portland, OR 97230-1089, USA \\ ${ }^{4}$ The Weather Channel, 300 Interstate North Parkway, Atlanta, GA 30339, USA \\ Correspondence should be addressed to Patrick S. Market; marketp@missouri.edu
}

Received 14 November 2014; Revised 7 May 2015; Accepted 25 May 2015

Academic Editor: Klaus Dethloff

Copyright ( 2016 Katie L. Crandall et al. This is an open access article distributed under the Creative Commons Attribution License, which permits unrestricted use, distribution, and reproduction in any medium, provided the original work is properly cited.

An extended version of the $Q$-vector form for the $\omega$-equation that includes diabatic (in particular latent) heating in the $Q$-vector itself is derived and tested for use in analyzing the life-cycle of a midlatitude cyclone that developed over the central United States during 24-26 December 2009. While the inclusion of diabatic heating in the $Q$-vector $\omega$-equation is not unique to this work, the inclusion of diabatic heating in the $Q$-vector itself is a unique formulation. Here it is shown that the diabatic $Q$-vector gives a better representation of the forcing contributing to the life-cycle of the Christmas Storm of 2009 using analyses derived from the 80-km NAM.

\section{Introduction}

For more than 60 years, quasigeostrophic theory (QG theory) has provided the underlying basis for techniques that explain the existence or evolution of a wide range of atmospheric phenomena including cyclones (e.g., [1-3]) and blocking anticyclones (e.g., [4-8]). QG theory has also been used and continues to be used, as a guiding principle in weather analysis and forecasting (e.g., [1,9-11]). QG theory represents a scaling of the primitive equations using the concept of approximate equality between the horizontal pressure gradient force and Coriolis (inertial) force in a two-dimensional atmosphere. QG theory also represents an acknowledgement that atmospheric circulations are three-dimensional but that the vertical components of these circulations are much weaker than their horizontal counterparts, and these serve to restore geostrophic and hydrostatic balance. In the earlier applications of QG theory (e.g., [1]), the atmosphere is assumed to be adiabatic, which neglects the role of diabatic processes (such as latent heat) and surface friction. Also, in model simulations or in diagnostic studies, large-scale vertical motions are typically calculated subject to an initially QG balanced environment (e.g., [12]).

Given advances in the understanding of the lifecycles of atmospheric phenomena as well as advances in computing power, there are many studies which have examined the role of forcing neglected in earlier studies using QG equations in midlatitude cyclones (e.g., [13-18]). These have included processes such as boundary layer friction, boundary layer sensible heating, or latent heat release. These have even been included in the study of large-scale phenomena such as blocking anticyclones (e.g., [19-21]), more specifically midlatitude ridging due to lower tropospheric diabatic heating. By including processes or forcing such as diabatic heating or friction in the study of these phenomena, a better understanding of their life-cycle evolution has been gained. This has resulted in better model formulations of, for example, convection (e.g., [22]), as well as providing better guidance to operational forecasters. 
While many of the diagnostic tools used in meteorological analysis were developed in full form, such as the omega equation (e.g., [23]) or the Zwack-Okossi vorticity tendency equation (e.g., $[5,16])$, they have primarily been used in QG form in many studies (e.g., [24-27]). An increase in computing power has been one factor in inspiring the use of more complete forms of these diagnostic equations (e.g., $[4,13,16,20,28])$, and these publications, as well as others, initially refer to the QG-equations that include latent heat and/or friction as "extended" QG forms. In recent years, these "extended" equations are referred to as QG forms, dropping the "extended" notation. The increase in computing power has also led to the development of new expressions, such as the ageostrophic vorticity tendency equation (e.g., [18]). These new diagnostic quantities have allowed the user to examine the role of traditional atmospheric forcing processes using a more complete framework.

The role of diabatic heating in forcing ascent (e.g., latent heating) has long been included by researchers for use in the diagnostic equations cited in examples above. Other examples include the studies of [29], who developed and [30] later used a $Q$-vector form of the $\omega$-equation. Then [30] further included latent heating on the right hand side of the equation as an additional forcing process. In [30], a cyclone case occurring over the Iberian Peninsula was studied, and the latent heating was included in their Q-vector equation in order to examine the role of this process in the cyclone. Both studies demonstrated that the inclusion of latent heating provided a better estimate for the divergence field that is associated with vertical motion. Thus, in both of their work, the divergence of $\mathbf{Q}$ was calculated separately from the Laplacian of latent heating in order to determine the role of this process in cyclone development.

The standard Q-vector equation [25] is used heavily in operational analysis and forecasting as it amalgamates important QG forcing processes into one variable (e.g., $[17,25,26])$. In the standard formulation of the $Q$-vector, the differential vorticity advection and the Laplacian of the temperature advection are combined to form a term that contains the advection of the temperature by the gradient of the wind field. This has some important advantages, such as eliminating "overlap" between the differential vorticity advection and the Laplacian of the temperature advection and the fact that the forcing is Galilean invariant (e.g., [31]).

Diabatic heating of any kind is not included regularly in any formulation of $\mathbf{Q}$ known to the authors. Since diabatic heating (in particular latent heating) has been shown to be a contributor to the development of phenomena such as midlatitude cyclones, it is often included in diagnostic studies using, for example, the omega equation. Since there is a $Q-$ vector form of the omega equation, it would be useful to develop a $Q$-vector expression that includes the contribution of diabatic heating inside the one variable $\mathbf{Q}$. Thus, this is the goal of the work here, and the details will be presented in Section 2. In Sections 3 and 4, we perform a case study of a synoptic-scale cyclone where diabatic heating (in particular tropospheric latent heating) was an important process and demonstrate the effectiveness and utility of the diabatic Qvector. Section 5 will summarize the work done here and present our conclusions.

\section{Data and Methods}

2.1. Derivation of an Extended Q-Vector Form of the $\omega$-Equation and a Diabatic Q-Vector. The derivation of an extended $Q$-vector is similar to the QG version found in [32]. This derivation begins with a quasigeostrophic form of the NavierStokes equations ((1a), (1b), and (1c)) here:

$$
\begin{aligned}
& \frac{d u_{g}}{d t_{g}}=f_{o} v_{a g}+\beta y v_{g}+\vec{F}_{x} \\
& \frac{d v_{g}}{d t_{g}}=-f_{o} u_{a g}-\beta y u_{g}+\vec{F}_{y} \\
& \frac{d}{d t_{g}}=\frac{\partial}{\partial t}+u_{g} \frac{\partial}{\partial x}+v_{g} \frac{\partial}{\partial y},
\end{aligned}
$$

where $u$ and $v$ are the zonal and meridional wind components, respectively. The subscripts " $g$ " and " $a g$ " represent a geostrophic or ageostrophic wind, respectively. The Coriolis parameter is $f_{o}$ and the change in the Coriolis parameter in the meridional direction is represented by $\beta$. Friction is represented by " $F$." The complete derivation of the $Q$-vector can be found in [10].

Then, following, for example, $[10,26,30]$ and others, we arrive at (2a) and (2b) the final extended $Q$-vector form:

$$
\begin{aligned}
Q_{1} e= & \frac{\partial \omega}{\partial x}-\frac{f_{o}^{2}}{\sigma} \frac{\partial u_{a g}}{\partial p} \\
= & -2 \frac{R}{\sigma p}\left(\frac{\partial \vec{V}_{g}}{\partial x} \cdot \nabla T\right)+\frac{R}{\sigma p} \beta y \frac{\partial T}{\partial y} \\
Q_{2} e= & \frac{\partial \omega}{\partial y}-\frac{f_{o}^{2}}{\sigma} \frac{\partial v_{a g}}{\partial p} \frac{\partial}{\partial x}\left(\frac{\dot{H}}{c_{p}}\right)-\frac{f_{o}}{\sigma} \frac{\partial}{\partial p} \frac{\partial \vec{F}_{y}}{\partial x} \\
= & -2 \frac{R}{\sigma p}\left(\frac{\partial \vec{V}_{g}}{\partial y} \cdot \nabla T\right)-\frac{R}{\sigma p} \beta y \frac{\partial T}{\partial x} \\
& -\frac{R}{p \sigma} \frac{\partial}{\partial y}\left(\frac{\dot{H}}{c_{p}}\right)+\frac{f_{o}}{\sigma} \frac{\partial}{\partial p} \frac{\partial \vec{F}_{x}}{\partial y},
\end{aligned}
$$

where

$$
\vec{Q}=Q_{1} e \hat{i}+Q_{2} e \widehat{j} .
$$

In (2a), (2b), and (2c), $H$ is used for the diabatic heating instead of the traditional notation of $Q$ in order to avoid confusion with the $Q$-vector. Taking the partial derivative 
of (2a) and (2b) with respect to $x(y)$, adding the two parts together, and using continuity in the form

$$
\nabla \cdot \vec{V}=\left(\frac{\partial u_{a g}}{\partial x}+\frac{\partial v_{a g}}{\partial y}\right)=-\frac{\partial \omega}{\partial p},
$$

result in (4a), (4b), and (4c). Consider the following:

$$
\begin{aligned}
\left(\nabla^{2}+\frac{f_{o}^{2}}{\sigma} \frac{\partial^{2}}{\partial p^{2}}\right) \omega= & -\underbrace{2 \nabla \cdot \vec{Q}}_{\mathrm{A}}-\underbrace{\frac{R}{\sigma p} \beta \frac{\partial T}{\partial x}}_{\mathrm{B}}-\underbrace{\frac{R}{\sigma p} \nabla^{2} \frac{\dot{H}}{c_{p}}}_{\mathrm{C}} \\
& +\underbrace{\frac{f_{o}}{\sigma} \frac{\partial}{\partial p} \widehat{k} \cdot(\nabla \times \vec{F})}_{\mathrm{D}},
\end{aligned}
$$

where $\mathbf{Q}$ is now comprised of the traditional $Q$-vector:

$$
\begin{aligned}
& Q_{1}=-\frac{R}{\sigma p}\left(\frac{\partial \vec{V}_{g}}{\partial x} \cdot \nabla T\right) \\
& Q_{2}=-\frac{R}{\sigma p}\left(\frac{\partial \vec{V}_{g}}{\partial y} \cdot \nabla T\right) .
\end{aligned}
$$

The result is a traditional form of the $Q$-vector relationship ((4b) and (4c)) derived by [25] originally and found in [32] in QG form, respectively. In (4a), Term A is the divergence of $\mathbf{Q}$, Term B is the "Beta Term" (meridional difference in the Coriolis parameter), Term $\mathrm{C}$ is the diabatic heating term, and Term D is the friction term. Further, for the "extended" forms derived by those cited in section one, they also state that the observed winds can be used in the calculation instead of their geostrophic values.

However, one of the results of the [25] Q-vector derivation was that the differential vorticity and the Laplacian of the temperature advection terms in the $\omega$-equation were combined. Since the Laplacian operator is the divergence of the gradient operator, or $(\nabla \cdot \nabla),(4 \mathrm{a}),(4 \mathrm{~b})$, and $(4 \mathrm{c})$ can be rewritten as;

$$
\begin{aligned}
\left(\nabla^{2}+\frac{f_{o}^{2}}{\sigma} \frac{\partial^{2}}{\partial p^{2}}\right) \omega= & -2 \nabla \cdot \overrightarrow{\widetilde{Q}}-\frac{R}{\sigma p} \beta \frac{\partial T}{\partial x}+\frac{f_{o}}{\sigma} \frac{\partial}{\partial p} \widehat{k} \\
& \cdot(\nabla \times \vec{F})
\end{aligned}
$$

where $\widetilde{Q}$ now has the components

$$
\begin{aligned}
& \widetilde{Q}_{1}=-\frac{R}{\sigma p}\left(\frac{\partial \vec{V}_{g}}{\partial x} \cdot \nabla T-\frac{1}{2} \frac{\partial}{\partial x} \frac{\dot{H}}{c_{p}}\right) \\
& \widetilde{Q}_{2}=-\frac{R}{\sigma p}\left(\frac{\partial \vec{V}_{g}}{\partial y} \cdot \nabla T-\frac{1}{2} \frac{\partial}{\partial y} \frac{\dot{H}}{c_{p}}\right),
\end{aligned}
$$

and the diabatic heating term is now clearly part of the Qvector formulation ((5b) and (5c)) and the divergence of $\mathbf{Q}$ and not a separate term as in $[29,30]$. Thus, the goal of this study will not be to demonstrate primarily the importance of diabatic heating in contributing to cyclone development, since that has been established by many researchers, but the utility of a diabatic Q-vector in an operational context. Nonetheless, it will be compared to the traditional $Q$-vector as a point of reference. It is also noted here that this study only examines the latent heating in the diabatic $Q$-vector and sensible and radiational heating/cooling process are neglected.

2.2. Data and Analysis. Numerical output from the North American Mesoscale (NAM) Eta model was used to make the calculations of the diabatic $Q$-vector and its components. In particular, a thinned, $80 \mathrm{~km}$ grid was employed for the QG diagnostics as suggested by [33]. While this is relatively coarse resolution compared to what is used operationally today, these data were readily available in-house. The operational resolution at the time of this storm was $12 \mathrm{~km}$ out to $84 \mathrm{~h}$. Output was taken from the run initialized at 1200 UTC 24 December 2009. At this time, a well-developed cyclone was already present over the southern United States, as suggested by both the surface analysis (showing a mature cyclone) and the satellite signature of a comma cloud in the southern plains (see Figure 1).

Given its initial position, the cyclone was well sampled by the observing network for the center of the circulation especially over the land areas of the United States. Grids from the NAM solutions were thus selected at 12 hours (0000 UTC 25 December 2009) and 24 hours (1200 UTC 25 December 2009) into the run. This approach allows time for the NAM Eta model run to become dynamically balanced and still be early enough to prevent serious departures from reality. As a result, the vertical motions that are produced by the model do not include subgrid-scale process. Thus the vertical motions would be result of larger-scale QG processes and parameterizations of latent heating and friction (documentation for the NAM can be found on the website such as http://www.srh.noaa.gov/ssd/nwpmodel/html/nam.html). Nonhydrostatic versions of the model with finer resolution are able to produce vertical motions with latent heat included.

2.3. Latent Heating Calculation. GEMPAK [34] was used to process the NAM model grids and to format and produce estimates of $\widetilde{Q}_{1}(5 b)$ and $\widetilde{Q}_{2}(5 c)$. Consistent with the formulations of these expressions, it is important to note that these $Q$-vectors were constructed using a single level only $(500 \mathrm{hPa})$, requiring fewer calculations. This is an advantage over techniques that would require multiple levels for a calculation (e.g., [16]). Moreover, the static stability is held constant so that the entire leading term, as $-R / \sigma p$, is constant; this also promotes a more direct comparison to the traditional $Q$-vector. Additionally, the actual temperature, $T$, in $\widetilde{Q}_{1}$ and $\widetilde{Q}_{2}$ is replaced with the potential temperature, $\theta$, which also is more in keeping with traditional formulations of the $Q$ vector and facilitates use of the method employed effectively by [35] and derived by [36] and for estimating the diabatic (specifically latent) heating:

$$
\dot{H}=\frac{d \theta}{d t}=\omega\left(\frac{\partial \theta}{\partial p}-\frac{\gamma_{m}}{\gamma_{d}} \frac{\theta}{\theta_{e}} \frac{\partial \theta_{e}}{\partial p}\right) .
$$




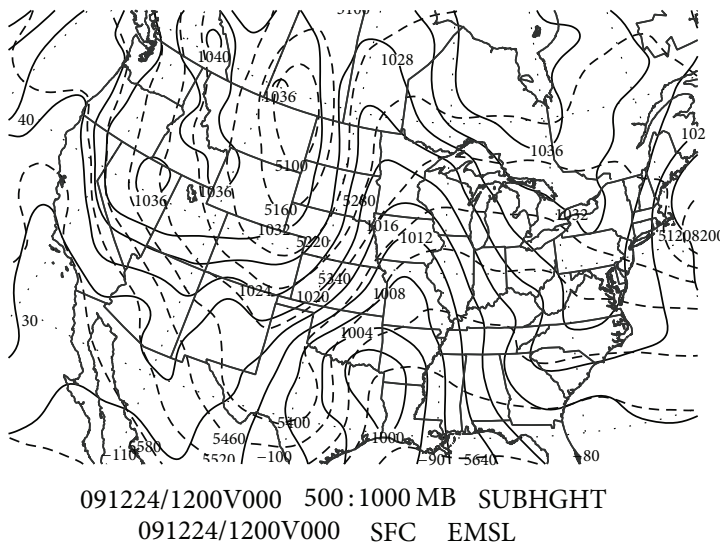

(a)

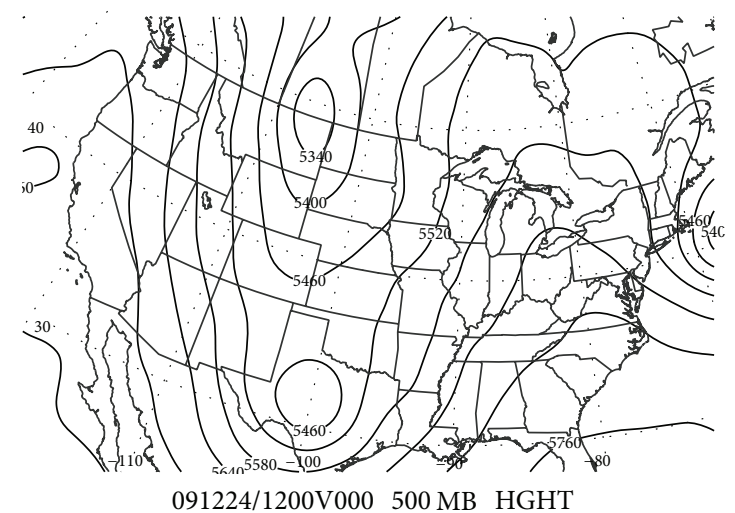

(b)

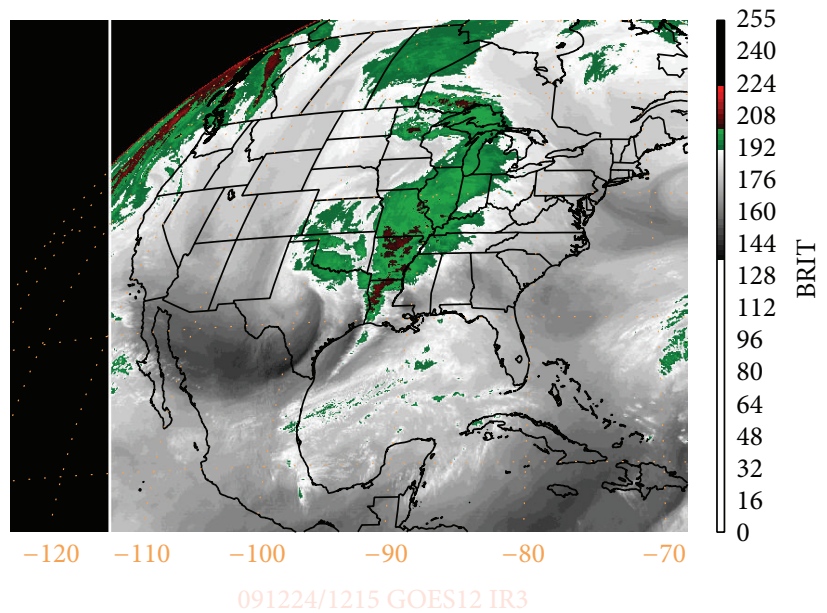

(c)

FIGURE 1: Maps and analyses for 1200 UTC 24 December 2009, where (a) is the mean sea level pressure (solid, every 4 hPa) and 1000-500-hPa geopotential thickness (dashed, every $60 \mathrm{gpm}$ ) from NAM Eta initialization, (b) the $500 \mathrm{hPa}$ geopotential heights (solid, every 60 gpm), and (c) the GOES-12 water vapor image at 1215 UTC.

In (6) $\gamma_{m}$ and $\gamma_{d}$ are the moist- and dry-adiabatic lapse rates, $\theta_{e}$ is the equivalent potential temperature, and the rest of the variables have their usual meanings. Equation (6) was derived in [36] using the concept of moist entropy, and the details can be found in this work. This formulation is also similar to that used in [30]. This computation uses the model vertical motion to calculate latent heating. The new calculated vertical motion can be then used to recalculate latent heating iteratively (e.g., use the new vertical motion in the latent heating and recalculate vertical motion); however, subsequent calculations do not improve the result significantly. This strategy is used often in latent heat calculations (e.g., $[16,18,20])$.

\section{Synoptic Analysis}

The cyclone to be examined here occurred during Christmas 2009 and brought a variety of weather to the mid-Mississippi Valley region as well as the Southern Plains of North America. This included 41 tornadoes, 24 high wind reports, and 10 hail reports in the southern Mississippi Valley region, especially Louisiana, as well as heavy rain and snow to points further north (http://www.spc.noaa.gov/). As of 1200 UTC 23 December 2009 (not shown), the surface cyclone was a weak and unorganized area of low pressure located over the Southern Plains near Texas and Oklahoma with the minimum pressures around $1001 \mathrm{hPa}$. At $500 \mathrm{hPa}$, there was a strong trough and strong meridional flow over the western portion of the United States, and the strongest winds at $300 \mathrm{hPa}$ were located on the upstream side of the trough. However, the coldest air was still located over western Canada at this time and was beginning to move southward into the Plains region.

By 1200 UTC 24 December 2009 (the time of NAM model initialization used here), the surface low was located over eastern Texas and the surface pressure was $998 \mathrm{hPa}$ (Figure 1(a)). Blizzard conditions existed over Oklahoma near this time and even included reports of thundersnow, though thundersnow events are not geographically favored in this region [37]. There was strong midlevel meridional flow over the western United States extending deep into Texas, and the trough itself (with a closed center over Texas) had not moved appreciably eastward; instead, the trough and ridge over the United States amplified substantially and the trough 


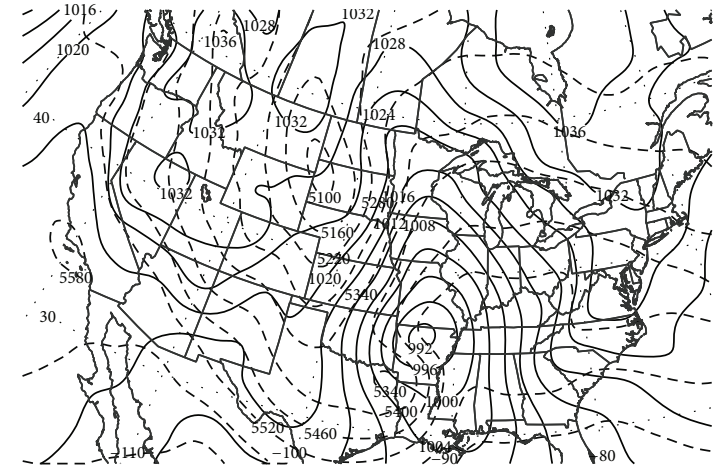

091225/0000V000 500:1000 MB SUBHGHT 091225/0000V000 SFC EMSL

(a)

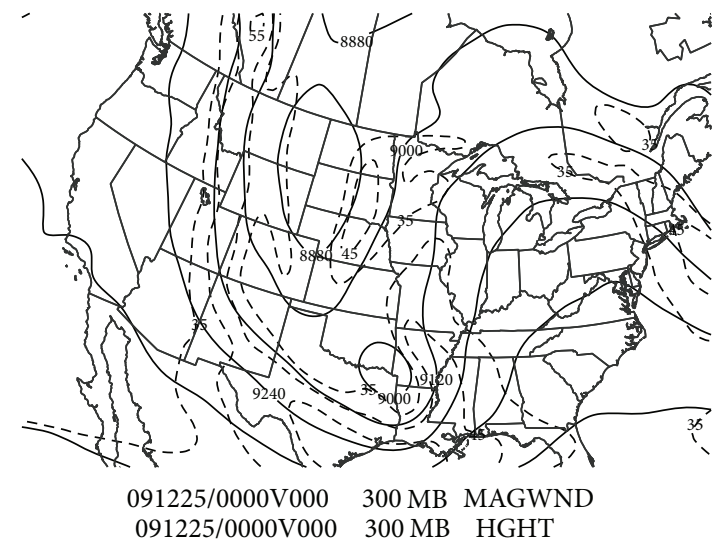

(c)

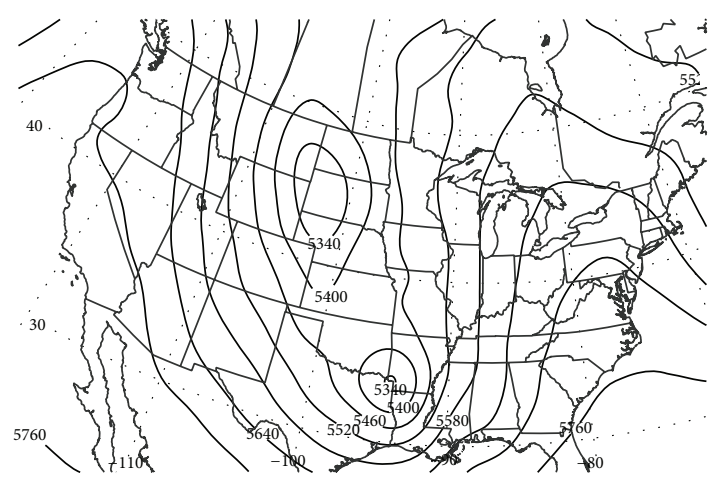

091225/0000V000 500 MB HGHT

(b)

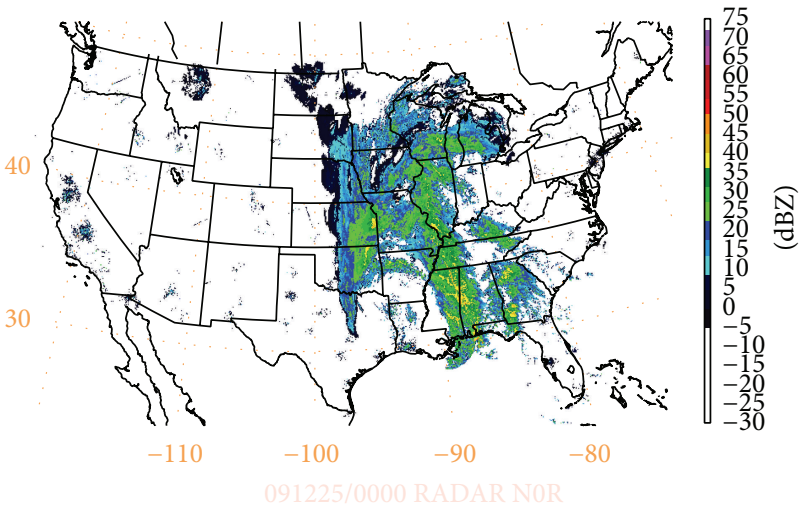

(d)

Figure 2: Maps and analyses for 0000 UTC 25 December 2009, where (a) is the mean sea level pressure (solid, every 4 hPa) and 1000-500-hPa geopotential thickness (dashed, every 60 gpm) from NAM Eta initialization, (b) the $500 \mathrm{hPa}$ geopotential heights (solid, every 60 gpm), (c) the 300-hPa geopotential heights (solid, every $120 \mathrm{gpm}$ ) and the wind speeds (dashed, every $10 \mathrm{~ms}^{-1}$, at $35 \mathrm{~ms}^{-1}, 45 \mathrm{~ms}^{-1}$, and $55 \mathrm{~ms}^{-1}$ ), and (d) the Doppler radar base reflectivity mosaic.

narrowed (Figure 1(b)). Satellite imagery suggested a welldeveloped, mature cyclone, with a comma signature featuring two southern cloud bands suggesting complex flows within the warm conveyor belt (Figure 1(c)).

Over the next $24 \mathrm{~h}$, the surface cyclone deepened (Figure 2(a)) concurrent with the intensifying $500 \mathrm{hPa}$ low (Figure 2(b)) and attendant upper-level jet structure (Figure 2(c)), more specifically the exit region of the cyclonically curved jet (e.g., [38]). The precipitation shield at 0000 UTC 25 December 2009 (Figure 2(d)) emphasizes the maturity of the system. By 1200 UTC 25 December 2009, the surface cyclone had reached $\sim 990 \mathrm{hPa}$ (Figure 3(a)). The cyclone has also occluded, based upon Bergeron's rule of analysis, that a frontal wave is occluded if the pressure difference between the cyclone center and the last closed isobar is $15 \mathrm{hPa}$ or greater [39]. At $500 \mathrm{hPa}$ (Figure 3(b)), the upper level low deepened significantly (more than $120 \mathrm{~m}$ in $24 \mathrm{hr}$ ) over the central United States and had become a closed system with four closed contours. At $300 \mathrm{hPa}$ (not shown, deepened about $200 \mathrm{~m}$ ), the trough was located over the same region and mirrored the evolution of the $500 \mathrm{hPa}$ trough over the same $24 \mathrm{hr}$ period but has only one closed contour by this time.
Up to this time, the trough is tilted westward with height in the lower troposphere indicating baroclinic development. Generally, cyclones that were studied in the references above show strong surface development in terms of rapid central pressure falls. This storm showed midtropospheric development, without strong pressure falls in the surface cyclone (only $8 \mathrm{hPa}$ in $24 \mathrm{hr}$ ). It is suspected here that the midlevel deepening was due in part to latent heating above this level based on previous studies (e.g., [16, 40,41]), though a study of the entire heating profile would be needed to verify this scenario. Nonetheless, [40] show that mid and upper level latent heating would have little impact on surface development. Also, the impact of diabatic (latent) heating diminishes with distance from the maximum (e.g., [41]).

At 0000 UTC 26 December 2009, the satellite perspective shows that this storm was of large enough scale to have drawn in moisture from the southeast Pacific, the Gulf of Mexico, and the Atlantic (Figures 1(c) and 4). In fact, an examination of the 950-500 hPa relative humidity (not shown) showed a broad area of saturation (values greater than $80 \%$ ) across the upper midwest and plains states within the cyclone region (Figure 4) in the low- to midtroposphere. While high relative 


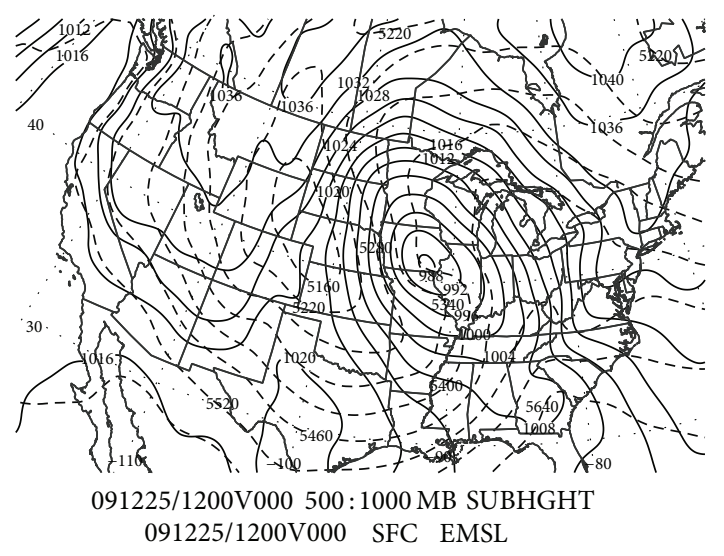

(a)

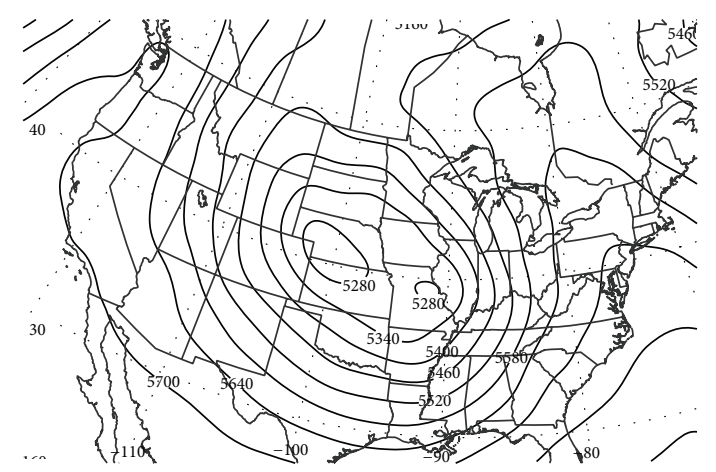

091225/1200V000 500 MB HGHT

(b)

Figure 3: As in Figures 1(a) and 1(b) except for 120025 December 2009.

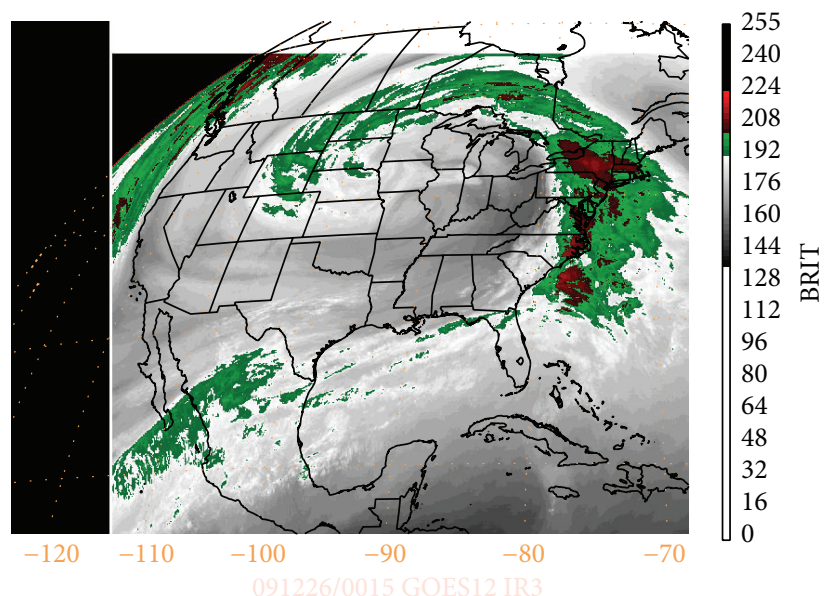

Figure 4: As in Figure 1(c), except for 001526 December 2009.

humidity values are often used to show where clouds and latent heating reside, it should be cautioned that these values do not reflect actual moisture values.

By 1200 UTC 26 December 2009, the surface cyclone began to fill; there would have been more low level convergence present than upper level divergence at the time, for example, $[16,40]$, and the pressures rose. The upper-level trough had become a closed low located over Wisconsin. The heaviest precipitation was located to the north and east of the surface cyclone, and a significant dry air stream had wrapped up into the Great Lakes region near the cyclone center. After this time, over the next $48 \mathrm{~h}$, the surface and midlevel cyclone would decay and fill before being swept out of the region by the next transient system (not shown).

\section{Dynamic Analysis and Discussion}

The traditional $Q$-vector (Figure 5(a)) and diabatic $Q$-vector (Figures 5(a) and 5(b)) were both used in order to examine the forcing for vertical motion associated with this cyclone at $500 \mathrm{hPa}$. The shaded regions here are the 6 -h precipitation greater than $4 \mathrm{~mm}$. Precipitation is shown here since it tends to correlate with latent heat release; however, there may be some differences as not all latent heat release results in precipitation. Latent heat release can also be associated with cloud formation, but significant latent heat release is associated with clouds that produce precipitation. Recall that precipitation is the result of moisture, lift, and instability, and these are represented (6) shown in section two. In this section, the vertical motion is examined using the diabatic $Q$-vector equation, which is a diagnostic equation. Thus, this section will illustrate the relative contribution of latent heating only in the diabatic Q-vector.

At 0000 UTC 25 December 2009 (Figure 5(a)), the $12 \mathrm{~h}$ NAM model solutions show that the traditional $Q$-vector divergence included only relatively strong forcing due to the vorticity and temperature advections over the region from Arkansas and surrounding areas and weak forcing elsewhere in the figure. This would only partially explain the development of the midtropospheric low over extreme southwest Arkansas (Figure 2(b)) by this time. Inclusion of latent heating (presumably maximizing above the $500 \mathrm{hPa}$ level, e.g., [16, 20]) in the $Q$-vector produced only slightly weaker forcing in the Q-vector during this time (Figures 5(b) and 5(e)). The region of forcing is a single, globular region even in the diabatic $Q$-vector field, broadly mimicking the comma shape seen in the satellite imagery. Presumably, by this time the forcing due to latent heat release has yet to fully materialize.

The divergence of $Q$ (Figure 5(c)) showed a pattern consistent with that of the $Q$-vector magnitudes (Figure 5(a)); as the magnitudes of the $Q$-vectors were small, the $Q$-vector convergence was weaker. However, the divergence of the diabatic $Q$-vector field (Figure 5(d)), while similar to the banded pattern in the field of diabatic Q-vector magnitude, reveals nicely the expected displacements of the divergence maxima into the gradients of the raw vector magnitudes. Moreover, the divergence of the standard $Q$-vector field revealed a circular area of divergence (and forcing for descent) across much of Missouri, where precipitation was actively falling both in the model and in reality (Figure 2(d)). Yet, the adiabatic 


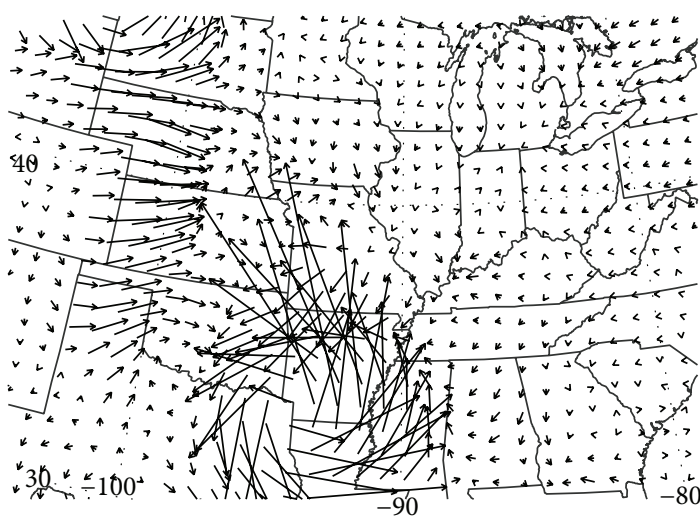

091225/0000V012500 MB ( $\left.{ }^{*} 10^{* *} 10\right)$

(a)

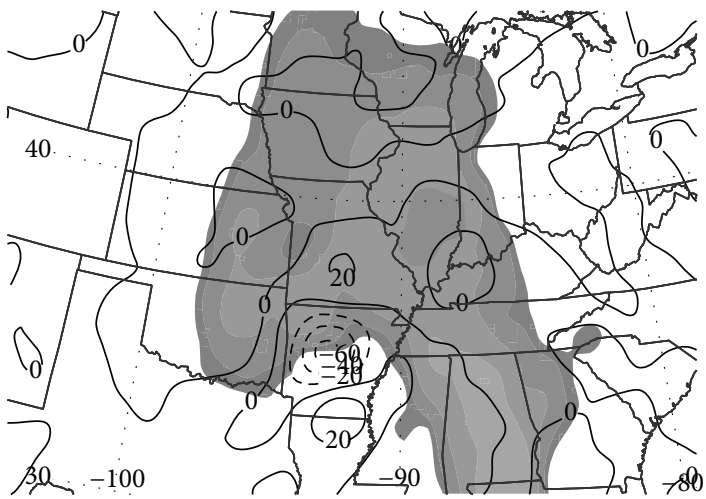

091225/0600V018 SFC P06M 091225/0000V012 500 MB DIVQVECTHTA $\left({ }^{*} 10^{* *} 15\right)$

(c)

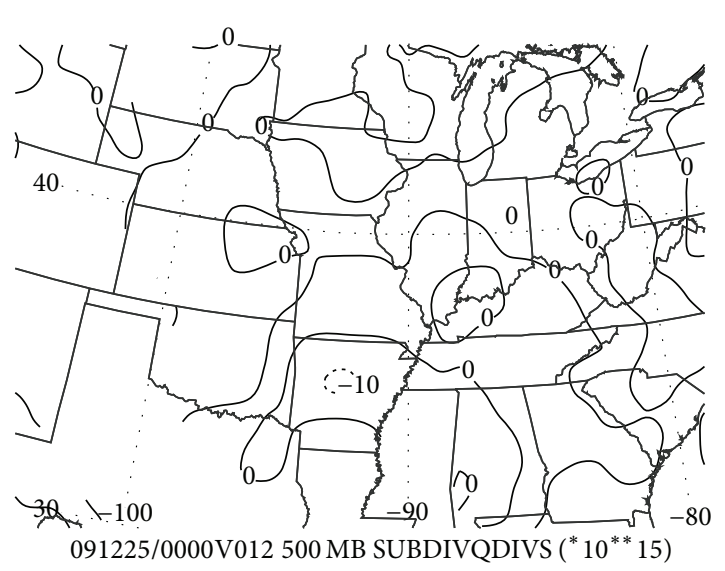

(e)

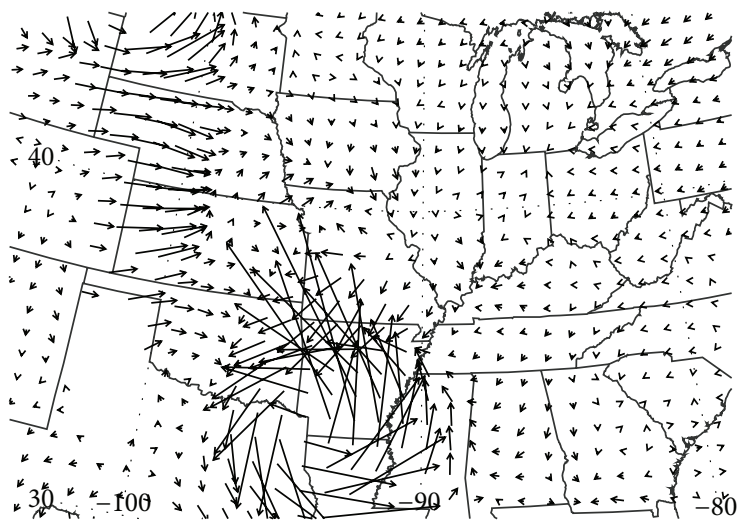

$091225 / 0000 \mathrm{~V} 012500 \mathrm{MB}\left({ }^{*} 10^{* *} 10\right)$

(b)

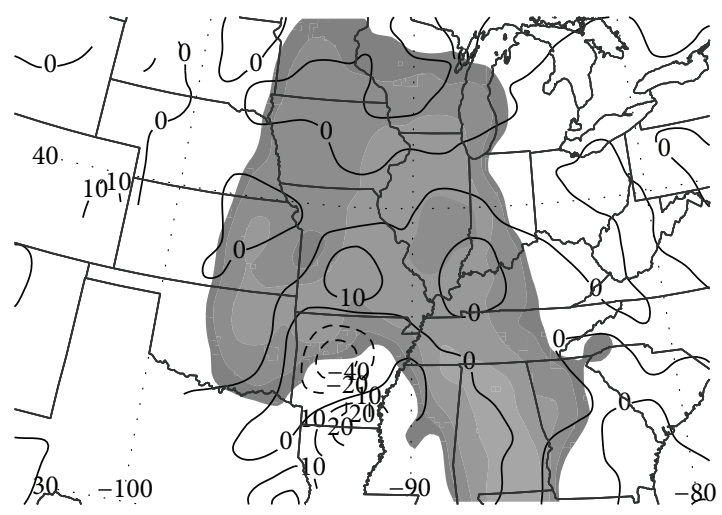

091225/0600V018 SFC P06M

091225/0000V012 500 MB DIVSMUL - $1.0\left({ }^{*} 10^{* *} 15\right)$

(d)

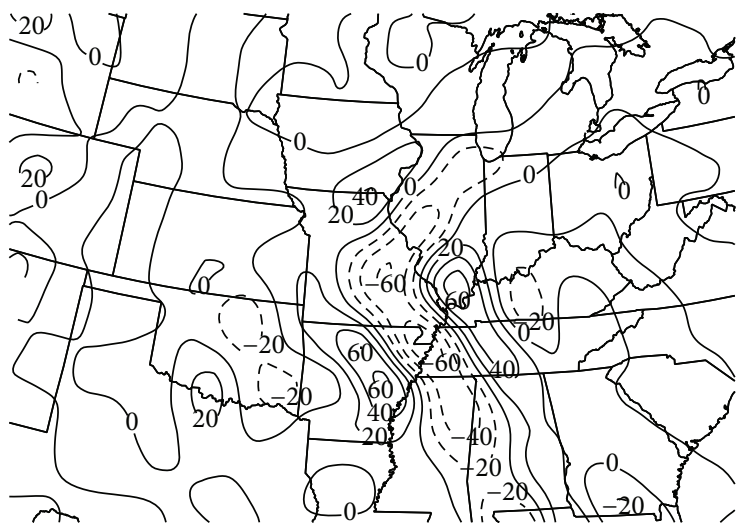

091225/0000V012 500 MB MULQUODLAPO $\left({ }^{*} 10^{* *} 15\right)$

(f)

Figure 5: Q-vector diagnostics from the NAM model run initialized at 1200 UTC 24 December 2009 and valid at 0000 UTC 25 December 2009 (12-hour solutions), including (a) standard 500-hPa Q $\left(\mathrm{hPa} \mathrm{m}^{-1} \mathrm{~s}^{-1}\right)$, (b) the diabatic form of the 500-hPa Q (hPa $\left.\mathrm{m}^{-1} \mathrm{~s}^{-1}\right)$, (c) the divergence of the standard $500-\mathrm{hPa}, \nabla \cdot \overrightarrow{\mathrm{Q}}$ (every $20 \times 10^{-15} \mathrm{hPa} \mathrm{m}^{-2} \mathrm{~s}^{-1}$; values $<0$ are dashed; values of 0 or greater are solid), (d) the divergence of the diabatic form of the $500-\mathrm{hPa}, \nabla \cdot \vec{Q}$ (every $20 \times 10^{-15} \mathrm{hPa} \mathrm{m}^{-1} \mathrm{~s}^{-1}$; values $<0$ are dashed; values of 0 or greater are solid), (e) the difference in divergence between the standard and diabatic forms of the $500-\mathrm{hPa} Q$ (every $10 \times 10^{-15} \mathrm{hPa} \mathrm{m}^{-1} \mathrm{~s}^{-1}$; values $<0$ are dashed; values of 0 or greater are solid), and (f) the Laplacian of pressure vertical motion, $-(1 / 2) \nabla^{2} \omega$ (every $20 \times 10^{-15} \mathrm{hPa} \mathrm{m}^{-1} \mathrm{~s}^{-1}$; values $<0$ are dashed; values of 0 or greater are solid). Frames (c) and (d) also feature the 6-hour precipitation (shaded at 2, 4, 10, and 20 mm), accumulated in the model in the ensuing 6-hour period, ending at 0600 UTC 25 December 2009. 


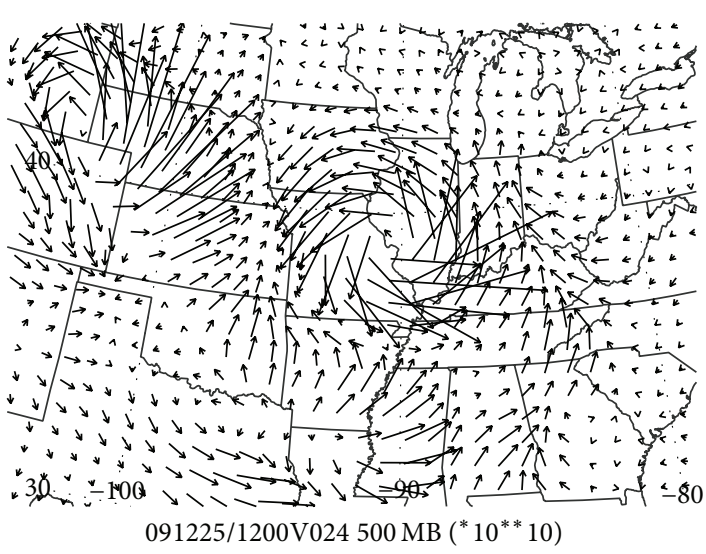

(a)

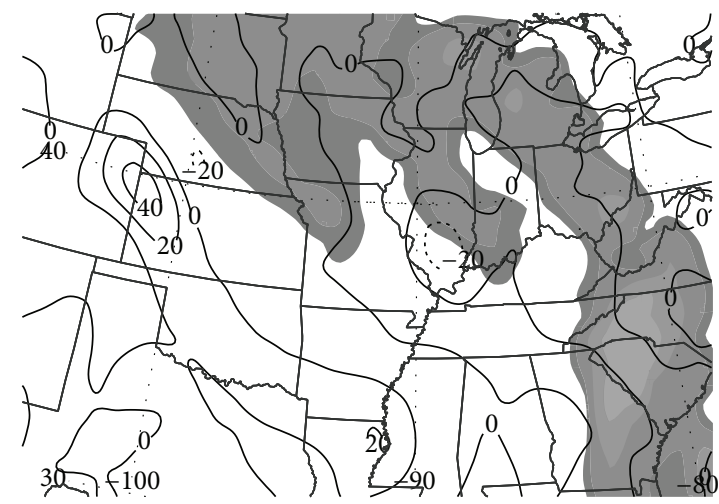

091225/1800V030 SFC P06M

091225/1200V024 500 MB DIVQVECTHTA $\left({ }^{*} 10^{* *} 15\right)$

(c)

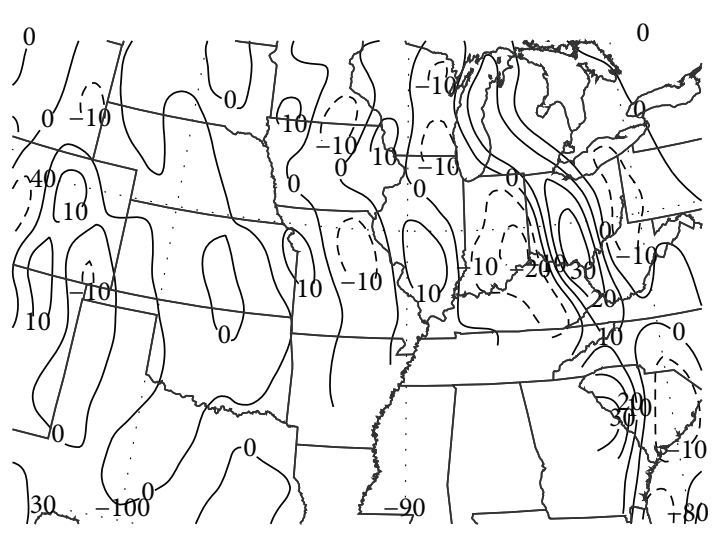

091225/1200V024 $500 \mathrm{MB}$ SUBDIVQDIVS $\left({ }^{*} 10^{* *} 15\right)$

(e)

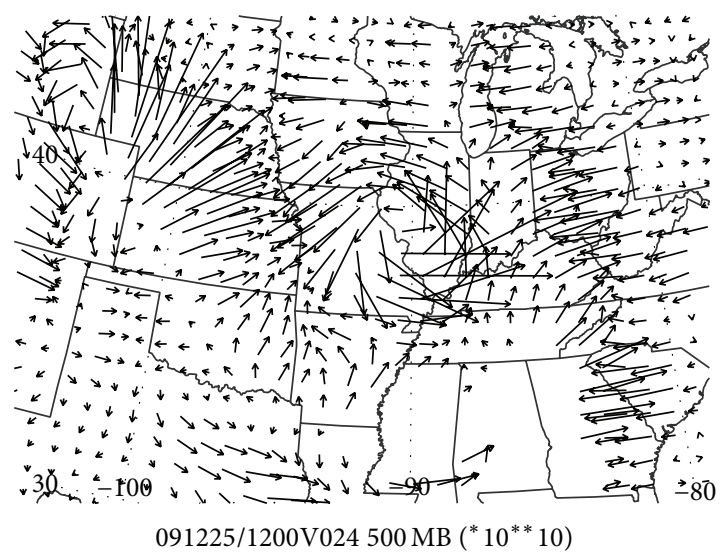

(b)

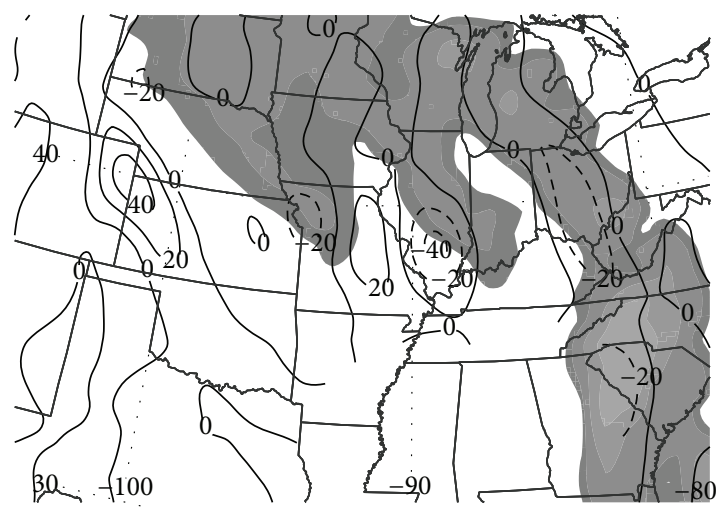

091225/1800V030 SFC P06M

091225/1200V024 $500 \mathrm{MB}$ DIVSMUL - $1.0\left({ }^{*} 10^{* *} 15\right)$

(d)

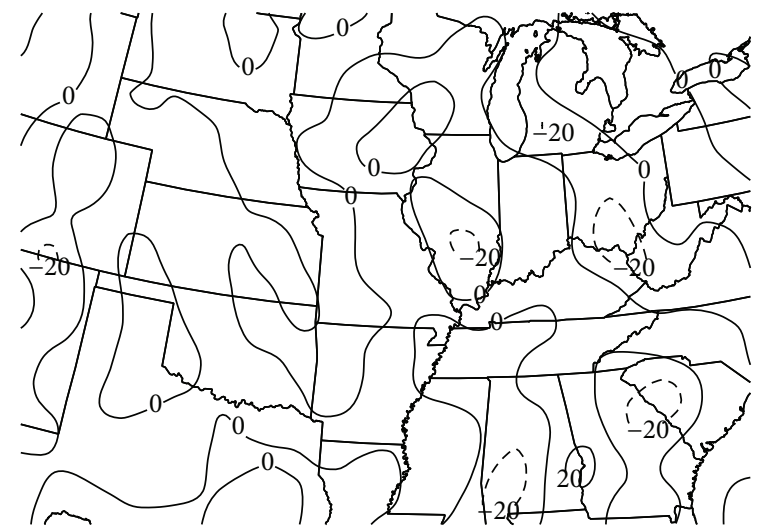

091225/1200V024 500 MB MULQUODLAPO $\left({ }^{*} 10^{* *} 15\right)$

(f)

FIGURE 6: As in Figure 5, but from the NAM model run initialized at 1200 UTC 24 December 2009 and valid at 1200 UTC 25 December 2009 (24-hour solutions).

diagnosis misses the stronger precipitation areas centered over western Illinois and central Alabama. The difference field of the divergence of standard $\mathbf{Q}$ is less the divergence of the diabatic $\mathbf{Q}$ (Figure 5(e)) and reveals a band of relatively large positive values across southeast Missouri, western Tennessee, and into northern Mississippi. Such values result from nearzero (positive or negative) values of standard $\mathbf{Q}$ divergence having large values of diabatic $\mathbf{Q}$ convergence subtracted from them. The regions of greatest positive differences run along and immediately adjacent to the most intense 6-hour model precipitation accumulations in the ensuing hours between 1200 UTC and 1800 UTC on 25 December 2009. The Laplacian of the $\omega$ field (Figure 5(f)) also matches nicely (pattern and magnitude) with the divergence pattern in both 
the traditional and diabatic $\mathbf{Q}$ field (Figure 5(d)) as well as the precipitation region, confirming the importance latent heating may have later and the calculation of the diabatic Qvector.

By 24 hours into the NAM simulation (1200 UTC 25 December 2009) the presence of a deep cyclone is reflected in both the standard Q-vector field (Figure 6(a)) and the diabatic $Q$-vectors (Figure 6(b)). Indeed the vector fields are much more similar over Missouri and Illinois, nearer the center of the circulation. To the east over Ohio, Kentucky, and West Virginia is where the larger differences occur at this time, associated with the warm sector and warm conveyor belt of the cyclone. The divergence of the standard $Q$-vector field is unrevealing where the model precipitation is accumulating (Figure 6(c)), with divergence values close to zero across much of Indiana and Ohio. The addition of the diabatic heating term to $\mathbf{Q}$ provides a divergence field (Figure 6(d)) with a clearly better correlation to the actual precipitation field that is accumulating in the model. The difference field between the divergences in the standard Q-vector and the diabatic $Q$-vector (Figure 6(e)) reveals maximum differences well-correlated with areas of stronger modeled precipitation over Ohio and southeastward into the Carolinas, further suggesting the limited utility of the standard Q-vector in diagnosing upward motions at this state in the cyclone's lifecycle. However, even in the Illinois region where presumably dynamic forcing is dominant, the diabatic Qvector is stronger (Figure 6(e)). Moreover, the Laplacian of $\omega$ (Figure 6(f)) suggests ascent over locations such as Ohio and South Carolina, where precipitation was occurring in the model. Finally, the differences between the traditional divergence of $\mathbf{Q}$ calculations and the diabatic $Q$-vectors were larger in Figure 6 which is later in the cyclone life-cycle than in Figure 5. This is because the gradients in the diabatic heating were larger in Figure 6 as implied by the divergence of $\mathbf{Q}$ calculations which include the gradient of diabatic heating.

\section{Summary and Conclusions}

An extended version of the $Q$-vector is developed here that includes diabatic heating as a forcing term in the divergence of $\mathbf{Q}$ itself, amalgamated with the differential vorticity advection and the Laplacian of the temperature advection terms. While this version of the $Q$-vector could include latent heat release, sensible, or radiational heating/cooling, only latent heat release is included in this study for the purpose of demonstration. A strong cyclone, which developed over the central United States during 24-26 December 2009, was studied using output from the NAM Eta model with a resolution of $12 \mathrm{~km}$, thinned to $80 \mathrm{~km}$, in order to show the utility of this technique. This cyclone was different from many of the cyclones studied by those cited in section one in that the development in the middle troposphere leading to the formation of a closed cyclone was studied. Also, in the referenced studies, a strong surface development occurred, which did not happen in this case. Additionally, this event was of such scale that it drew in moisture from the three major moisture sources bordering the United States.
The dynamic analysis showed that the diabatic Q-vector (in this case latent heating only) revealed stronger midtropospheric forcing associated with this storm than the traditional $Q$-vector. Thus, this form of the $Q$-vector would have been more useful in this case from an operational perspective as it would have indicated the stronger forcing aloft, especially later in the lifecycle of the storm following the stronger precipitation associated with the event. Further study testing the utility of this technique will be performed with more cyclone events.

The traditional Q-vector identified the general region where there was forcing that was favorable to cyclone development acting to generate upward motions and height falls but was significantly weaker overall. The diabatic $Q$-vector was stronger, especially later in the lifecycle and identified $Q$-vector convergence in the warm moist air ahead of the cyclone that was not identified using the traditional formulation. While the importance of diabatic processes has been previously established, this comparison was made in order to demonstrate the utility and ease of calculating a diabatic $Q$-vector. Presumably, the diabatic Q-vector would possess all of the advantages of the traditional model including the nonlinear interaction between the three forcing terms and Galilean Invariance. This technique also allowed the use of analyses produced from coarser resolution model output and using only one pressure level for the computations.

\section{Conflict of Interests}

The authors declare that there is no conflict of interests regarding the publication of this paper.

\section{Acknowledgments}

The authors are indebted to Dr. Scott Rochette for his insightful review of this paper. Dr. Louis Uccellini also offered useful comments during early phases of this work. The authors also wish to thank the anonymous reviewers for making this paper a stronger contribution.

\section{References}

[1] S. Petterssen, Weather Analysis and Forecasting, vol. 1, McGrawHill, New York, NY, USA, 2nd edition, 1956.

[2] G. J. Hakim, D. K. Keyser, and L. F. Bosart, "The Ohio Valley wave-merger cyclogenesis event of 25-26 January 1978. Part I: a multiscale case study," Monthly Weather Review, vol. 123, pp. 2663-2692, 1995.

[3] G. J. Hakim, D. K. Keyser, and L. F. Bosart, "The Ohio Valley wave-merger cyclogenesis event of 25-26 January 1978. Part II: diagnosis using quasigeostrophic potential vorticity inversion," Monthly Weather Review, vol. 124, no. 10, pp. 2176-2205, 1996.

[4] C. H. Tsou and P. J. Smith, "The role of synoptic/planetary-scale interactions during the development of a blocking anticyclone," Tellus, Series A, vol. 42, no. 1, pp. 174-193, 1990.

[5] A. R. Lupo and P. J. Smith, "Planetary and synoptic-scale interactions during the life cycle of a mid-latitude blocking anticyclone over the North Atlantic," Tellus, Series A, vol. 47, pp. 575-596, 1995. 
[6] J. P. Burkhardt and A. R. Lupo, "The planetary- and synopticscale interactions in a southeast Pacific blocking episode using PV diagnostics," Journal of the Atmospheric Sciences, vol. 62, no. 6, pp. 1901-1916, 2005.

[7] A. R. Lupo, I. I. Mokhov, M. G. Akperov, A. V. Chernokulsky, and H. Athar, "A dynamic analysis of the role of the planetaryand synoptic-scale in the summer of 2010 blocking episodes over the european part of russia," Advances in Meteorology, vol. 2012, Article ID 584257, 11 pages, 2012.

[8] A. D. Jensen and A. R. Lupo, "Using enstrophy advection as a diagnostic to identify blocking-regime transition," Quarterly Journal of the Royal Meteorological Society, vol. 140, no. 682, pp. 1677-1683, 2014.

[9] T. N. Carlson, Mid-Latitude Weather Systems, American Meteorological Society, 1998.

[10] J. R. Holton, An Introduction to Dynamic Meteorology, Elsevier, 4th edition, 2004.

[11] J. E. Martin, Mid-Latitude Atmospheric Dynamics: A First Course, John Wiley \& Sons, 2006.

[12] M. Boettcher and H. Wernli, "Life cycle study of a diabatic rossby wave as a precursor to rapid cyclogenesis in the North Atlantic-dynamics and forecast performance," Monthly Weather Review, vol. 139, no. 6, pp. 1861-1878, 2011.

[13] C.-H. Tsou, P. J. Smith, and P. M. Pauley, "A comparison of adiabatic and diabatic forcing in an intense extratropical cyclone system," Monthly Weather Review, vol. 115, no. 4, pp. 763-786, 1987.

[14] C. A. Davis, M. T. Stoelinga, and Y. H. Kuo, "The integrated effect of condensation in numerical simulations of extratropical cyclogenesis," Monthly Weather Review, vol. 121, no. 8, pp. 23092330, 1993.

[15] M. T. Stoelinga, "A potential vorticity-based study of the role of diabatic heating and friction in a numerically simulated baroclinic cyclone," Monthly Weather Review, vol. 124, no. 5, pp. 849-874, 1996.

[16] A. R. Lupo, P. J. Smith, and P. Zwack, "A diagnosis of the explosive development of two extratropical cyclones," Monthly Weather Review, vol. 120, no. 8, pp. 1490-1523, 1992.

[17] A. R. Lupo, P. S. Market, S. E. Mudrick et al., "An analysis of a long-lived MCV observed over the Southern plains using potential vorticity diagnostics," National Weather Digest, vol. 24, no. 3, pp. 17-26, 2000.

[18] A. R. Lupo, "The role of ageostrophic forcing in a height tendency equation," Monthly Weather Review, vol. 130, no. 1, pp. 115126, 2002.

[19] F. J. Sáez de Adana and S. J. Colucci, "Southern Hemisphere blocking onsets associated with upper-tropospheric divergence anomalies," Journal of the Atmospheric Sciences, vol. 62, no. 5, pp. 1614-1625, 2005.

[20] D. E. Tilly, A. R. Lupo, C. J. Melick, and P. S. Market, "Calculated height tendencies in two southern hemisphere blocking and cyclone events: the contribution of diabatic heating to block intensification," Monthly Weather Review, vol. 136, no. 9, pp. 3568-3578, 2008.

[21] A. D. Jensen and A. R. Lupo, "The role of deformation and other quantities in an equation for enstrophy as applied to atmospheric blocking," Dynamics of Atmospheres and Oceans, vol. 66, pp. 151-159, 2014.

[22] J. S. Kain and J. M. Fritsch, "Multiscale convective overturning in mesoscale convective systems: reconciling observations, simulations, and theory," Monthly Weather Review, vol. 126, no. 8, pp. 2254-2273, 1998.
[23] T. N. Krishnamurti, "A diagnostic balance model for studies of weather systems of low and high latitudes, Rossby Number less than 1," Monthly Weather Review, vol. 96, no. 4, pp. 197-207, 1968.

[24] P. Zwack and B. Okossi, "A new method for solving the quasigeostrophic omega equation by incorporating surface pressure tendency data," Monthly Weather Review, vol. 114, no. 4, pp. 655666, 1986.

[25] B. J. Hoskins, I. Draghici, and H. C. Davies, "A new look at the $\omega$ equation," Quarterly Journal of the Royal Meteorological Society, vol. 104, pp. 31-38, 1978.

[26] B. J. Hoskins, M. E. McIntyre, and A. W. Robertson, "On the use and significance of isentropic potential vorticity maps," Quarterly Journal of the Royal Meteorological Society, vol. 111, no. 470, pp. 877-946, 1985.

[27] A. R. Lupo and L. F. Bosart, "An analysis of a relatively rare case of continental blocking," Quarterly Journal of the Royal Meteorological Society, vol. 125, no. 553, pp. 107-138, 1999.

[28] J. M. Vasilj and P. J. Smith, "A comparison of extended and quasigeostrophic dynamics for a case of small-Rossby number extratropical cyclone development," Monthly Weather Review, vol. 125, no. 12, pp. 3347-3356, 1997.

[29] L. F. Bosart, "Weather forecasting," in Handbook of Applied Meteorology, D. D. Houghton, Ed., pp. 205-280, John Wiley \& Sons, New York, NY, USA, 1985.

[30] M. L. Martin, M. Y. Luna, and F. Valero, "Evidence for the role of the diabatic heating in synoptic-scale processes: a case study example," Annales Geophysicae, vol. 15, no. 4, pp. 487-493, 1997.

[31] M. K. Walters, "A simple example of Galilean invariance in the omega equation," Bulletin of the American Meteorological Society, vol. 82, no. 3, pp. 463-472, 2001.

[32] H. B. Bluestein, Synoptic-Dynamic Meteorology in the MidLatitudes Vol I: Principles of Kinematics and Dynamics, Oxford University Press, 1992.

[33] S. L. Barnes, F. Caracena, and A. Marroquin, "Extracting synoptic-scale diagnostic information from mesoscale models: the eta model, gravity waves, and quasigeostrophic diagnostics," Bulletin of the American Meteorological Society, vol. 77, no. 3, pp. 519-528, 1996.

[34] S. E. Koch, M. Desjardins, and P. J. Kocin, "An interactive Barnes objective map analysis scheme for use with satellite and conventional data," Journal of Climate and Applied Meteorology, vol. 22, no. 9, pp. 1487-1503, 1983.

[35] J.-P. Cammas, D. Keyser, G. Lackmann, and J. Molinari, “Diabatic redistribution of potential vorticity accompanying the development of an outflow jet within a strong extratropical cyclone," in Proceedings of the International Symposium on the Life Cycles of Extratropical Cyclones, pp. 403-409, American Meteorological Society, Bergen, Norway, 1994.

[36] K. A. Emanuel, M. Fantini, and A. J. Thorpe, "Baroclinic instability in an environment of small stability to slantwise moist convection. Part I: two-dimensional models," Journal of the Atmospheric Sciences, vol. 44, no. 12, pp. 1559-1573, 1987.

[37] P. S. Market, C. E. Halcomb, and R. L. Ebert, "A climatology of thundersnow events over the contiguous United States," Weather and Forecasting, vol. 17, no. 6, pp. 1290-1295, 2002.

[38] J. T. Moore and G. E. Van Knowe, "The effect of jet-streak curvature on kinematic fields," Monthly Weather Review, vol. 120, no. 11, pp. 2429-2441, 1992.

[39] W. J. Saucier, Principles of Meteorological Analysis, University of Chicago Press, 1955. 
[40] R. L. M. Rausch and P. J. Smith, "A diagnosis of a model-simulated explosively developing extratropical cyclone," Monthly Weather Review, vol. 124, no. 5, pp. 875-904, 1996.

[41] P. J. Smith, "The importance of the horizontal distribution of heating during extratropical cyclone development," Monthly Weather Review, vol. 128, no. 10, pp. 3692-3694, 2000. 

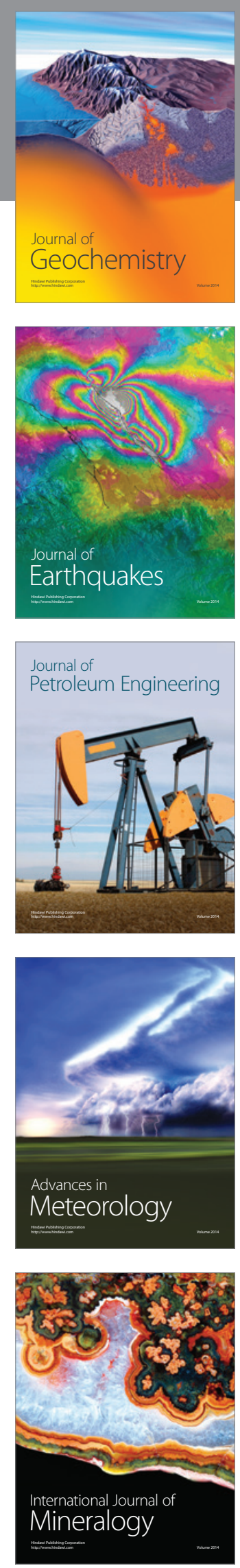
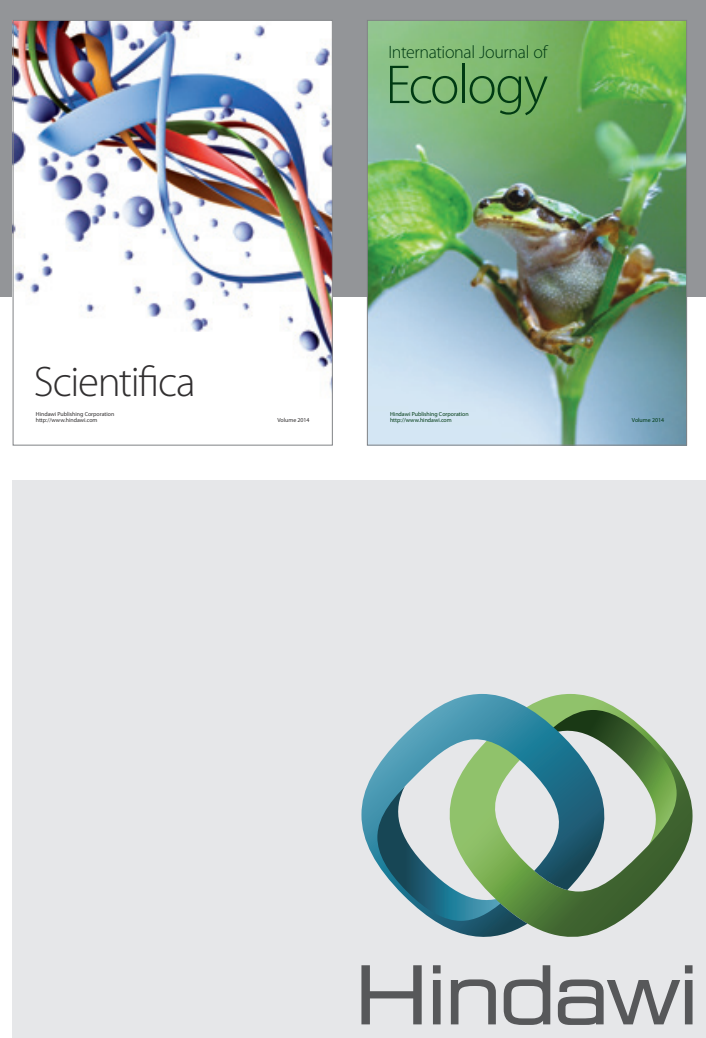

Submit your manuscripts at

http://www.hindawi.com
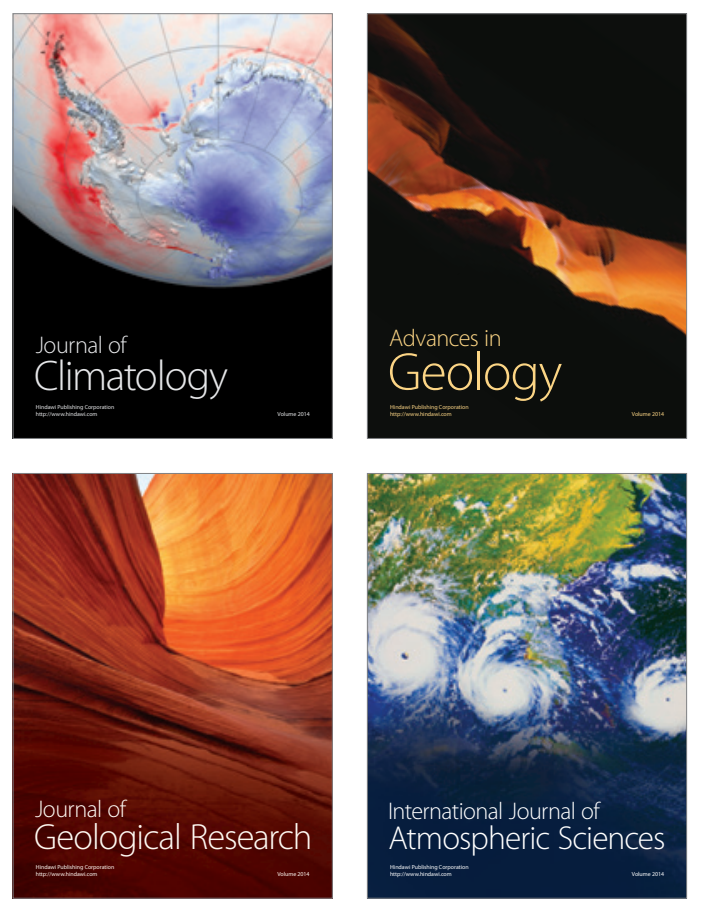

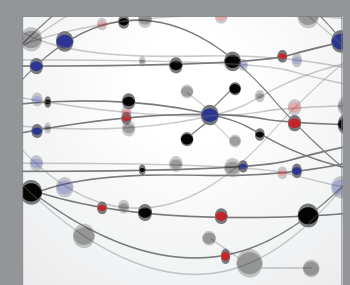

The Scientific

\section{World Journal}
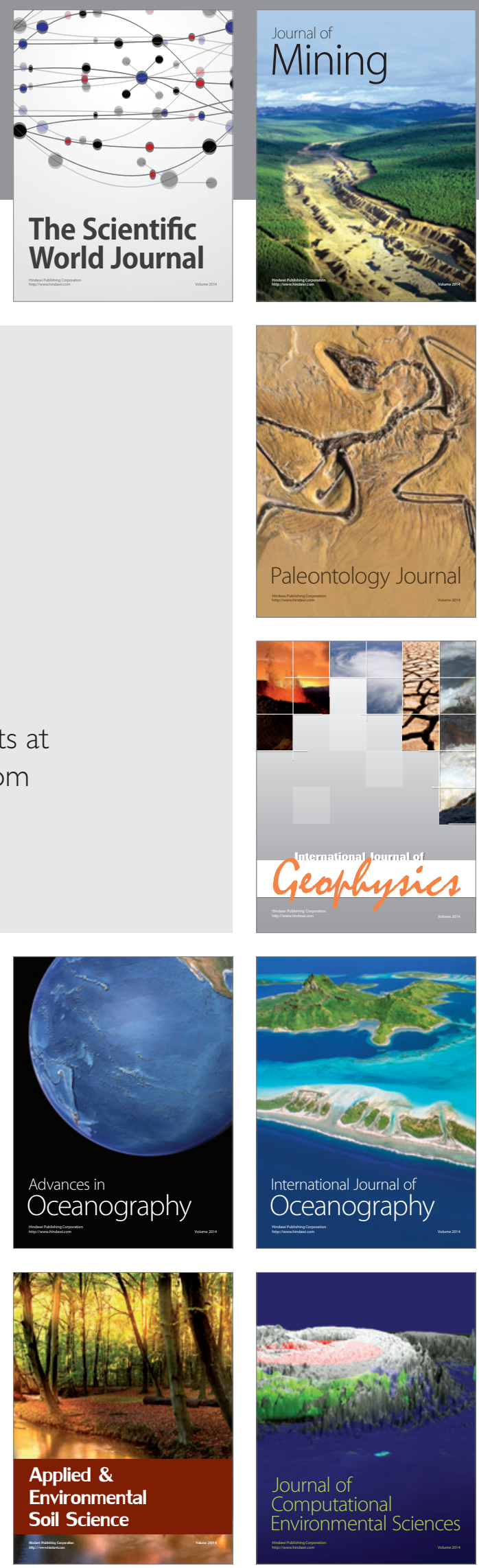